\title{
Multifactorial immunodeficiency in frail elderly patients: contributing factors and
} management

\section{Immunodépression multifactorielle de la personne âgée fragile : facteurs favorisants et prise en charge}

T TANNOU ${ }^{1,2,3}$, S KOEBERLE ${ }^{1,2}$, P MANCKOUNDIA ${ }^{4}$, R AUBRY ${ }^{1,2,3}$

1. Service de gériatrie, Hôpital J. Minjoz, CHU de Besançon, 3 Boulevard A. Fleming, 25030 Besançon Cedex

2. Axe Éthique et Progrès - Inserm $\mathrm{ClC} 1431, \mathrm{CHU}$ de Besançon, France

3. EA 481 Neurosciences, Université Bourgogne Franche Comté, Besançon, France.

4. Service - Médecine Interne Gériatrie, Pôle Personnes Âgées, CHU Dijon Bourgogne. Hôpital de Champmaillot - 2, rue Jules Violle - 21079 Dijon Cedex.

\author{
Corresponding author \\ Dr Thomas TANNOU \\ Chef de clinique - Assistant \\ Service de gériatrie \\ CHRU J. Minjoz \\ Boulevard A. Fleming - 25030 BESANCON Cedex \\ ttannou@chu-besancon.fr \\ $T e l: 03.81 .66 .91 .79$
}

Mots clés : personne âgée, dénutrition, immunosénescence

Keywords: elderly, malnutrition, immunosenescence 


\section{Résumé}

L'immunodépression du sujet âgé est multifactorielle. L'analyse des facteurs étiologiques démontre un rôle majeur de l'immunosénescence et de la dénutrition protéino-énergétique (DPE) avec carences en oligo-éléments comme la vitamine $D$, le zinc ou la vitamine $E$, dont la prévalence est importante chez les plus de 75 ans. Cette DPE participe aux nombreuses conséquences décrites dans le syndrome de fragilité et notamment d'une susceptibilité particulière aux infections, dont les infections fongiques, habituellement apanage des patients immunodéprimés, ce qui impose une vigilance particulière. Or, ces particularités du vieillissement du système immunitaire et de la vulnérabilité inhérente à l'avancée en âge peuvent conduire à une errance diagnostique puis à une escalade thérapeutique, notamment en antibiotiques, ainsi qu'à une perte de temps entraînant une perte de chance pour le patient. De plus, cette escalade d'antibiotiques entraîne une pression de sélection microbiologique chez le sujet âgé fragile, délétère au long cours en cas d'infection(s) opportuniste(s). La conduite à tenir repose essentiellement sur le repérage et la prise en charge de la fragilité, en particulier sur son versant nutritionnel. Le repérage du risque nutritionnel, la prise en charge diététique, l'évaluation thymique et une approche fonctionnelle en sont les quatre piliers. Ces éléments s'intègrent dans le cadre d'une évaluation et d'une prise en charge globale gériatrique. 


\begin{abstract}
Immunodeficiency in the elderly is multifactorial. The analysis of etiological factors demonstrates the major role of immunosenescence and protein-energy malnutrition (PEM) with high prevalence deficiencies in micronutrients such as vitamin $D$, zinc, or vitamin $E$ in people aged above 75 years. PEM contributes to the numerous consequences of frailty syndrome, and mainly to susceptibility to infections including fungal infections, which are usually observed in immunodeficient patients. Particular attention should thus be paid to these patients. However, these peculiarities of the immune system aging and the aging-related vulnerability can lead to diagnostic delays and treatment escalation, mainly with antibiotics, as well as to a loss of time resulting in a loss of opportunity for patients. Antibiotic escalation also leads to microbiological selection pressure in frail elderly people, which can be deleterious in the long-term in case of opportunistic infections. Guidelines are mainly based on the identification and management of frailty, especially in terms of nutrition. The identification of nutritional risk, dietary management, mood vigilance, and a functional approach are the four pillars of the management strategy. These elements are part of a global geriatric assessment and care.
\end{abstract}




\section{INTRODUCTION}

Physicians may be unaware of the specificities of the immune system aging. This lack of knowledge may lead to diagnostic delays and antibiotic therapy escalation. Treatment escalation, mainly antibiotic therapies, is associated with microbiological selection pressure [1] in elderly people. This microbiological selection pressure is even stronger in frail elderly patients as it is associated with a long-term negative impact in case of opportunistic infections. Besides immunosenescence, frail elderly people often present with severe protein-energy malnutrition (PEM) [2]. PEM contributes to the numerous consequences of frailty syndrome [3], and mainly to susceptibility to infections including fungal infections, which are usually observed in immunodeficient patients [4]. The combination of immunosenescence [5] and PEM-induced micronutrient deficiency [6] is associated with immunodeficiency in frail elderly people. They are more likely to contract infections caused by unusual bacteria [7]; particular attention should thus be paid to these patients [8].

We aimed to outline immunological evolution in elderly people presenting with frailty syndrome, screening options for these at-risk patients, and management modalities. We performed a literature analysis using the following MeSH terms on the PubMed and Google Scholar databases: "inflammaging", "immunosenescence", "frail elderly", and "undernutrition". We mainly focused on meta-analyses and systematic reviews.

\section{FACTORS CONTRIBUTING TO IMMUNODEFICIENCY IN ELDERLY PEOPLE}

Immunodeficiency in elderly people is multifactorial. Predisposing factors of immunodeficiency in elderly people are related to intrinsic factors such as genetic predisposition to immunosenescence or aging-related physiological changes, and to extrinsic factors such as undernourishment and some comorbidities or treatments.

\subsection{IMMUNOSENESCENCE}

The immune system helps the organism distinguish between self and non-self, and contributes to the defense against external aggressions. The immune system is made of physiological barriers (skin/mucous) and proteins and cellular agents enabling such identification. Damages to the immune system may be due to primary diseases of the immune system (lymphoproliferative or myeloproliferative disorders) or to secondary diseases. Although secondary factors are mainly due to 
environmental causes, they may also be explained by immune system impairment as part of the aging process, i.e. immunosenescence $[5,9]$. Besides impairment of cutaneous and mucosal barriers [10], aging also leads to substantial changes in the innate and adaptive immune systems. These changes depend on aging-related and environmental factors, the main factors being the reduced nutritional intake in proteins and micronutrients, but also comorbidities and iatrogenesis [11]. Elderly people are thus at higher risk of infections than younger individuals. The immune system is based on a two-step response ability [12]:

- on the one hand, an innate immunity based on the action of myeloid cells such as neutrophils, macrophages, dendritic cells, and natural killer cells (NK). This immunity is associated with a rapid and non-specific response, triggered by an external aggression. It is mainly based on the host's phagocytosis, lysis, and oxidation ability. To do so, it requires many lysosomal enzymes and proinflammatory cytokines. These protein responses occur as part of a synergistic process between the various activated cells, through chemotaxis. The innate immunity is usually triggered by macrophages [12];

- on the other hand, the adaptive (or specific) immunity is based on a slower activation and on a highly specific response. It is based on B cells and T cells, which are activated by the innate immune response mainly through dendritic cells and macrophages. These activated lymphocytes trigger a specific, cellular (cytotoxic), and/or humoral (via antibodies) response, as well as an immunological memory associated with a more rapid response for any later presentation of the same antigen [11].

Several changes pertain to the physiological aging of the immune system, known as immunosenescence:

- for the innate immunity, although no reduction in the absolute number of cells is observed, several changes are observed, except in dendritic cells. Reduced macrophage, cytotoxic, lysosomal, and oxidative activities are indeed observed as well as an impaired chemotaxis. Paradoxically, proinflammatory cytokines are hyperactivated by macrophages $[5,11,13,14]$;

- the adaptive immunity is most strongly impacted during immunosenescence. Although the number of cells is not reduced, their quality is highly impacted. A literature review 
performed by Crétel in 2010 [11] reported changes in the proportion of B cells between native cells and memory B cells, as well as an impaired antibody response as part of humoral immunity. This mainly leads to a dysfunction in the collaboration between $B$ cells and T cells, and to the impaired recognition of self and nonself. Low-specificity antibodies are therefore produced, which may explain the emergence of some clones in hematological disorders of the elderly. As for cellular immunity, an impaired adaptive immune response towards new pathogens, mainly intracellular pathogens, is observed. This is characterized by the accumulation - through clonal expansion - of memory B cells, mainly cytotoxic cells, because of an impaired apoptosis.

The hypersecretion of proinflammatory interleukins could be indicative of an adaptive mechanism compensating for the failure of immune mechanisms, and mainly those of innate immunity. Nonetheless, such adaptation known as "inflammaging" because of the aging-related chronic inflammation, could be involved in the development of numerous aging-related chronic disorders [15].

This evolution of immune system responses has led several authors to characterize an immunological frailty phenotype based on the CD4/CD8 lymphocyte ratio, a positive cytomegalovirus (CMV) serological test, the presence of cognitive disorders (mild or severe), and an increased interleukin (IL)-6 level [16].

Immunosenescence is therefore associated with (i) an increased susceptibility to infections, mainly to intracellular bacteria, (ii) a longer post-infection recovery, (iii) a lower sensitization to immunization, and (iv) an increased neoplastic and autoimmune susceptibility $[11,17]$. Immunity conferred by vaccination is also less effective [18]. However, these are just predisposing factors for the development of infections.

\subsection{IMPACT OF UNDERNOURISHMENT}

Besides changes related to immunosenescence, susceptibility to infections in the elderly is impacted by nutritional deficiencies. Yet, PEM is frequently observed in geriatric settings, especially in elderly people living in nursing homes [19]. The relation between immunodeficiency and PEM in the elderly is based on two factors: 
- on the one hand, the PEM-related hypercatabolism induced by the chronic inflammation and associated with the activation of macrophage proinflammatory cytokines, enhances the effects of PEM through the functional diversion of protein reserves. The phenomenon is thus enhanced and it triggers frailty syndrome-related sarcopenia $[3,15,20,21]$

- on the other hand, micronutrient deficiencies are associated with PEM which in turn exacerbates the immunosenescence phenomenon. Zinc, vitamin $D$, and vitamin $E$ deficiencies are particularly affected $[6,22]$. Zinc is the micronutrient involved in cell proliferation. It is crucial to the immune response. However, considering the organism's inability to stock zinc, deficiency in this micronutrient (serum level $<70 \mu \mathrm{g} / \mathrm{dL}$ ) is rapidly detrimental. Zinc deficiency has a synergistic effect on the various aspects of failure due to immunosenescence, thus reinforcing the latter phenomenon. Although several randomized studies reported the benefits of zinc supplementation on the immune response restoration, there is no consensus on dosing regimens [22]. Vitamin $E$ is an antioxidant that protects the cell membrane from oxidative stress. As this phenomenon is one of the mechanisms pertaining to the innate immunity functioning (NK cells), vitamin E plays a crucial role in preserving the integrity of cells during cytotoxic immune response. Epidemiological studies performed revealed the relation between infections and vitamin E deficiency. However, no consensus has been reached on the benefit of vitamin E supplementation in immune response restoration and on supplementation dosage [22]. The role of vitamin D in regulating mechanisms of calcium homeostasis is well-known. However, cells without any link with these functions harbor the vitamin D receptors. Biochemical studies revealed the predominance of vitamin $D$ receptors on immune cells. Vitamin D is believed to act as a fundamental stimulator of innate and adaptive immune responses. In terms of epidemiology, the relation between vitamin $D$ deficiency and immune susceptibility has also been highlighted [23]. However, unlike the action on phospho-calcium metabolism, there is no consensus on dosing regimens for substitution as part of this immune action $[22,23]$.

Besides immunosenescence, the presence of PEM and vitamin and micronutrient deficiencies in the elderly impairs the persistent immune response ability. Paradoxical inflammatory responses are therefore enhanced as well as deficiencies and PEM, leading to a frailty spiral [24]. 


\subsection{IMPACT OF COMORBIDITIES AND IATROGENESIS}

Besides effects of immunosenescence and PEM, the preservation of the immune system functioning is impaired by comorbidities and by the associated use of medications. A clear correlation has indeed been observed between the number of comorbidities and the decreased magnitude of immune response [25]. The immunosuppressive nature of some chronic diseases such as chronic obstructive pulmonary disease (COPD) or diabetes is well-known. Treatments such as corticosteroids exacerbate immunosuppression. In case of immunosenescence, the chronic inflammation may disturb the platelet aggregation activity and may reinforce the cardiovascular risk factors for atherosclerosis [26]. Finally, the use of antibiotics in severe situations disturbs the commensal flora and contributes to opportunistic infections, facilitated by the overall multifactorial immunodeficiency. Candidiasis, among other infections, is particularly likely to develop in these situations $[1,27-30]$.

\section{MANAGEMENT MODALITIES}

Multifactorial immunodeficiency should be considered a geriatric disorder [31], requiring systematic investigation of predisposing and eliciting factors [32].

Some predisposing factors for immunodeficiency cannot be modified, such as genetic predisposition to immunosenescence combined with the effects of aging. Others can be modified such as PEM, which can be corrected with nutritional guidance, or iatrogenic risk analysis requiring prescription review. Eliciting factors are related to added iatrogenesis, and mainly to the inappropriate use of antibiotics or corticosteroids. This check-up should be performed as part of the standardized geriatric assessment. It also contributes to identifying frailty criteria associated with inflammaging complications, mainly mood disorders [33].

\subsection{MANAGEMENT OF UNDERNOURISHMENT}

\subsubsection{DIAGNOSIS OF UNDERNOURISHMENT}

The French National Nutrition and Health Program (French acronym PNNS) defines PEM as a pathological state caused by the persistent incompatibility between the organism's metabolic needs and the bioavailability in energy and/or in proteins and/or in micronutrients. This definition has then been included in the arguments of guidelines issued by the French National Authority for Health (French acronym HAS). It can be due to the reduced nutritional intakes, irrespective of the 
mechanisms, and/or to the increased metabolic needs. PEM is characterized by a loss of lean body mass and often of body fat, especially in children. PEM is associated with measurable changes in physiological body functions responsible for these diseases' poorer prognosis [34].

PEM diagnosis should be considered because it contributes to frailty by enhancing inflammaging and leading to its self-sustaining $[24,35]$, and because it is often reversible with early and adequate management. The benefits of an early and adequate management have been proven in terms of overall improvement of the health status of frail elderly people, thus contributing to delaying dependency [36].

PEM screening should be performed in all patients at risk of PEM, mainly in case of hypercatabolism (neoplasia, inflammation, infection, organ failure) or in case of digestive absorption disorders. PEM should be looked for in the elderly presenting with psycho-social disorders and/or with impaired functional independence, oral cavity impairment, swallowing disorders, mood disorders, neurocognitive disorders, and polypharmacy [37].

Besides looking for previously reported risk factors, PEM screening is based on the evaluation of ingesta, weight and body mass index (BMI) measurement. The Mini-Nutritional Assessment - Short Form (MNA-Short Form) has been validated in PEM screening in the elderly [38,39].

PEM diagnosis relies on a mixed approach, combining clinical and biological criteria. At least one of the following criteria should be met to consider the diagnosis:

- at least $5 \%$ decrease in body weight within one month or at least $10 \%$ decrease within six months;

- $\quad B M I<21 \mathrm{~kg} / \mathrm{m}^{2}\left(\mathrm{BMI}>21 \mathrm{~kg} / \mathrm{m}^{2}\right.$ does not rule out PEM, especially in case of sarcopeniarelated obesity);

- albuminemia $<35 \mathrm{~g} / \mathrm{L}$ (inflammatory syndrome excluded);

- $\quad$ MNA total score $>17[40]$.

Severe PEM identification is fundamental because it is associated with poor prognosis and increased morbidity and mortality [37]. PEM is considered severe when at least one of the following criteria is met:

- $\quad \geq 10 \%$ weight loss within one month or $\geq 15 \%$ within six months;

- $\quad B M I<18 \mathrm{~kg} / \mathrm{m}^{2}$; 
- albuminemia $<30 \mathrm{~g} / \mathrm{L}$.

However, it should be reminded that hypoalbuminemia may be multifactorial in elderly people. Thus, hepatocellular failure or nephrotic syndrome should be ruled out before confirming that albuminemia is due to deficiencies in nutritional intake. Hypoalbuminemia is also a marker of catabolism in case of inflammatory response. Severe hypoalbuminemia in case of sepsis, although not enough to confirm PEM diagnosis, is however indicative of the absence of available reserves. This indicates frailty requiring management [35].

\subsubsection{MANAGEMENT STRATEGY OF UNDERNOURISHMENT}

PEM management strategy is initially based on the evaluation of food intake to check whether it is adapted to the individual's needs. Let us remind that the aim of nutritional management in undernourished elderly people is to reach a dietary energy consumption of at least 30 to $40 \mathrm{kcal} / \mathrm{kg} /$ day and a protein intake of at least 1.2 to $1.5 \mathrm{~g}$ of proteins $/ \mathrm{kg} /$ day. This is even more important in case of hypercatabolism, mainly in sepsis patients, as nutrient needs are increased [19].

Acute, inflammatory, and/or infectious presentations in undernourished elderly individuals presenting with hypercatabolism associated with immunosenescence and iatrogenesis should directly be managed adequately while initiating the etiological treatment. These are the recommendations of the HAS for severe PEM with reduced intakes through the systematic association of [34]:

- dietary advice;

- nutritional supplementation;

- oral nutritional complements;

- systematic reassessment at seven days to consider enteral nutrition in case of unfavorable outcome.

Considering vitamin and micronutrient deficiencies, as well as their impact on the immune response, vitamin D supplementation should be performed as 800 to $1,000 \mathrm{IU}$ per day to reach blood levels $>35 \mathrm{ng} / \mathrm{mL}$ [41]. Although no consensus has been reached in terms of dosing regimens, zinc and vitamin E supplementation seems relevant. Further studies are required to suggest specific management modalities. 


\subsection{MANAGEMENT OF COMORBIDITIES AND IATROGENESIS}

\subsubsection{STANDARDIZED GERIATRIC EVALUATION}

Standardized geriatric evaluation is a multidimensional approach aiming to determine the medical and functional status of elderly patients, particularly frail elderly patients, to support the management strategy [42].

This approach is based on screening for the main geriatric syndromes using validated scales such as MNA-SF for PEM, but also motor assessment tests such as the 4-meter gait speed test, Timed Up and Go Test, cognitive tests such as Mini-Mental Status Examination, or mood assessment using the geriatric depression scale (GDS). The standardized geriatric evaluation also includes an aptitude assessment in performing the most frequent daily life activities; this can be assessed using the Activity of Daily Living ( $A D L$ ) and instrumental ADL (iADL) scales, thus enabling re-assessment of the social environment. This assessment is performed by geriatricians to maximize the use of assessment tools according to patients' characteristics. On the basis of this assessment, physicians are able to suggest a global individualized management strategy for the various risk factors.

\subsubsection{TREATMENT REASSESSMENT}

Several tools have been developed to facilitate treatment adaptation in elderly patients, taking into consideration their comorbidities: DICTIAS tool, LAROCHE list, or START/STOPP criteria (validated French version). A literature review reported that among these tools, only the START/STOPP criteria were associated with a reduction in inappropriate prescriptions [43]. They can thus be used to review prescriptions.

\subsubsection{OVERALL MANAGEMENT OF FRAILTY}

Recent studies performed on the overall management of frailty reported the benefit of a multidisciplinary approach, with motor, cognitive, and nutritional stimulation [44]. This has been associated with muscle reinforcement and sarcopenia prevention [45]. Considering the mood impact of frailty, psychological support is required $[46,47]$.

\section{CONCLUSION}

In cases of acute infectious episode in elderly people, physicians should look for predisposing and eliciting factors that could indicate multifactorial immunodeficiency responsible for infections and 
potentially for opportunistic infections such as disseminated candidiasis. Predisposing factors for these infectious complications are:

- immunosenescence, responsible for impairment of the innate and adaptive immune systems and, by way of compensation, for increased latent hypercatabolism (inflammaging);

- presence of PEM;

- $\quad$ presence of multiple diseases;

- polypharmacy.

The use of broad-spectrum antibiotics and/or corticosteroids in acute situations is considered an eliciting factor for systemic or local opportunistic infections.

PEM plays a crucial role among these factors. It should therefore always be screened very early on, and early management should be implemented. Concomitant with screening and curative management, early management of other modifiable factors is required.

Such management is based on a standardized geriatric evaluation and, in acute situations, on the analysis of prescribed molecules to reduce the prescription of inadequate antibiotics, and also on a multidisciplinary management (mainly nutritional, mood, and motor management).

This overall multidisciplinary approach leads to the adequate management of elderly patients presenting with multifactorial immunodeficiency. 


\section{Disclosure of interests}

The authors declare no conflict of interests.

\section{Acknowledgment}

TT wrote the article. SK, PM, and RA reviewed the article. 


\section{REFERENCES}

1. Levy SB, Marshall B. Antibacterial resistance worldwide: causes, challenges and responses. Nat Med. 2004;10:S122-9.

2. Laur CV, McNicholl T, Valaitis R, Keller HH. Malnutrition or frailty? Overlap and evidence gaps in the diagnosis and treatment of frailty and malnutrition. Appl Physiol Nutr Metab. 2017;42:44958.

3. Jeejeebhoy KN. Malnutrition, fatigue, frailty, vulnerability, sarcopenia and cachexia: overlap of clinical features. Curr Opin Clin Nutr Metab Care. 2012;15:213-9.

4. De Pauw B, Walsh TJ, Donnelly JP, Stevens DA, Edwards JE, Calandra T, et al. Revised definitions of invasive fungal disease from the European Organization for Research and Treatment of Cancer/Invasive Fungal Infections Cooperative Group and the National Institute of Allergy and Infectious Diseases Mycoses Study Group (EORTC/MSG) Consensus Group. Clin Infect Dis Off Publ Infect Dis Soc Am. 2008;46:1813-21.

5. Gavazzi G, Krause K-H. Ageing and infection. Lancet Infect Dis. 2002;2:659-66.

6. Pae M, Meydani SN, Wu D. The Role of Nutrition in Enhancing Immunity in Aging. Aging Dis. 2011;3:91-129.

7. Hof H. Mycoses in the elderly. Eur J Clin Microbiol Infect Dis. 2010;29:5-13.

8. Htwe TH, Mushtaq A, Robinson SB, Rosher RB, Khardori N. Infection in the Elderly. Infect Dis Clin North Am. 2007;21:711-43.

9. Yoshikawa TT. Epidemiology and Unique Aspects of Aging and Infectious Diseases. Clin Infect Dis. 2000;30:931-3.

10. Fenske NA, Lober CW. Structural and functional changes of normal aging skin. J Am Acad Dermatol. 1986;15:571-85.

11. Crétel E, Veen I, Pierres A, Bongrand P, Gavazzi G. Immunosénescence et infections, mythe ou réalité ? Médecine Mal Infect. 2010;40:307-18.

12. Janeway CA, Murphy K, Travers P, Walport M. Immunobiologie. Paris: De Boeck Supérieur; 2009. $922 \mathrm{p}$.

13. Panda A, Arjona A, Sapey E, Bai F, Fikrig E, Montgomery RR, et al. Human innate immunosenescence: causes and consequences for immunity in old age. Trends Immunol. 2009;30:325-33.

14. Solana R, Tarazona R, Gayoso I, Lesur O, Dupuis G, Fulop T. Innate immunosenescence: Effect of aging on cells and receptors of the innate immune system in humans. Semin Immunol. 2012;24:331-41.

15. Franceschi C, Campisi J. Chronic Inflammation (Inflammaging) and Its Potential Contribution to Age-Associated Diseases. J Gerontol Ser A. 2014;69:S4-9. 
16. Wikby A, Ferguson F, Forsey R, Thompson J, Strindhall J, Löfgren S, et al. An Immune Risk Phenotype, Cognitive Impairment, and Survival in Very Late Life: Impact of Allostatic Load in Swedish Octogenarian and Nonagenarian Humans. J Gerontol Ser A. 2005;60:556-65.

17. Bürkle A, Caselli G, Franceschi C, Mariani E, Sansoni P, Santoni A, et al. Pathophysiology of ageing, longevity and age-related diseases. Immun Ageing. 2007;4:4.

18. Weinberger B, Herndler-Brandstetter D, Schwanninger A, Weiskopf D, Grubeck-Loebenstein B. Biology of Immune Responses to Vaccines in Elderly Persons. Clin Infect Dis. 2008;46:1078-84.

19. Patry C, Raynaud-Simon A. Prise en charge de la dénutrition chez les personnes âgées : quoi de neuf depuis les recommandations de I'HAS en 2007 ? NPG Neurol - Psychiatr - Gériatrie. 2011;11:95-100.

20. Moulias S. Nutrition et immunité de la personne âgée. Ann Med Interne. 2002;153:446-9.

21. Strandberg TE, Pitkälä KH, Tilvis RS. Frailty in older people. Eur Geriatr Med. 2011;2:344-55.

22. Pae $M$, Wu D. Nutritional modulation of age-related changes in the immune system and risk of infection. Nutr Res. 2017;41:14-35.

23. Holick MF. Vitamin D Deficiency. N Engl J Med. 2007;357:266-81.

24. Lang PO. Le processus de fragilité : que comprendre de la physiopathologie ? NPG Neurol Psychiatr - Gériatrie. 2013;13:28-34.

25. Castle SC, Uyemura K, Rafi A, Akande O, Makinodan T. Comorbidity Is a Better Predictor of Impaired Immunity than Chronological Age in Older Adults. J Am Geriatr Soc. 2005;53:1565-9.

26. Michaud M, Balardy L, Moulis G, Gaudin C, Peyrot C, Vellas B, et al. Proinflammatory Cytokines, Aging, and Age-Related Diseases. J Am Med Dir Assoc. 2013;14:877-82.

27. Sims CR, Ostrosky-Zeichner L, Rex JH. Invasive Candidiasis in Immunocompromised Hospitalized Patients. Arch Med Res. 2005;36:660-71.

28. Paillaud E, Merlier I, Dupeyron C, Scherman E, Poupon J, Bories P-N. Oral candidiasis and nutritional deficiencies in elderly hospitalised patients. Br J Nutr. 2004;92:861-867.

29. Akpan A, Morgan R. Oral candidiasis. Postgrad Med J. 2002;78:455-9.

30. Tannou T, Koeberle S, Bouiller K, Moreau J, Bellanger A-P, Aubry R. Candidose chronique disséminée chez une femme de 85 ans dénutrie. Médecine Mal Infect. 2017;47:361-3.

31. Inouye SK, Studenski S, Tinetti ME, Kuchel GA. Geriatric Syndromes: Clinical, Research, and Policy Implications of a Core Geriatric Concept. J Am Geriatr Soc. 2007;55:780-91.

32. Bouchon J-P. Particularités diagnostiques et grands principes thérapeutiques en gériatrie. EMC Médecine. 2004;1:513-9.

33. Brown PJ, Badreddine D, Roose SP, Rutherford B, Ayonayon HN, Yaffe K, et al. Muscle fatigability and depressive symptoms in later life. Int J Geriatr Psychiatry. 2017;32:e166-72. 
34. Haute Autorité de Santé. Stratégie de prise en charge en cas de dénutrition protéinoénergétique chez la personne âgée. 2007.

35. Don BR, Kaysen G. Poor Nutritional Status And Inflammation: Serum Albumin: Relationship to Inflammation and Nutrition. Semin Dial. 2004;17:432-7.

36. Calder PC, Bosco N, Bourdet-Sicard R, Capuron L, Delzenne N, Doré J, et al. Health relevance of the modification of low-grade inflammation in ageing (inflammageing) and the role of nutrition. Ageing Res Rev. 2017;40:95-119.

37. Ferry $M$, Mischlich D, Alix E, Brocker P, Constans T, Lesourd B, et al. Nutrition de la personne âgée. Paris: Elsevier Masson; 2012.

38. Vellas B, Guigoz Y, Garry PJ, Nourhashemi F, Bennahum D, Lauque S, et al. The mini nutritional assessment (MNA) and its use in grading the nutritional state of elderly patients. Nutrition. 1999;15:116-22.

39. Kaiser MJ, Bauer JM, Ramsch C, Uter W, Guigoz Y, Cederholm T, et al. Validation of the Mini Nutritional Assessment short-form (MNA ${ }^{\oplus}$-SF): A practical tool for identification of nutritional status. JNHA - J Nutr Health Aging. 2009;13:782.

40. Guigoz Y, Vellas B, Garry PJ. Assessing the nutritional status of the elderly: The Mini Nutritional Assessment as part of the geriatric evaluation. Nutr Rev. 1996;54:S59-65.

41. Bischoff-Ferrari HA, Giovannucci E, Willett WC, Dietrich T, Dawson-Hughes B. Estimation of optimal serum concentrations of 25 -hydroxyvitamin $D$ for multiple health outcomes. Am J Clin Nutr. 2006;84:18-28.

42. Ellis G, Gardner M, Tsiachristas A, Langhorne P, Burke O, Harwood RH, et al. Comprehensive geriatric assessment for older adults admitted to hospital. Cochrane Database Syst Rev. 2017;

43. Desnoyer A, Guignard B, Lang P-O, Desmeules J, Vogt-Ferrier N, Bonnabry P. Prescriptions médicamenteuses potentiellement inappropriées en gériatrie : quels outils utiliser pour les détecter ? Presse Médicale. 2016;45:957-70.

44. Dedeyne L, Deschodt M, Verschueren S, Tournoy J, Gielen E. Effects of multi-domain interventions in (pre)frail elderly on frailty, functional, and cognitive status: a systematic review. Clin Interv Aging. 2017;12:873-96.

45. Lozano-Montoya I, Correa-Pérez A, Abraha I, Soiza RL, Cherubini A, O’Mahony D, et al. Nonpharmacological interventions to treat physical frailty and sarcopenia in older patients: a systematic overview - the SENATOR Project ONTOP Series. Clin Interv Aging. 2017;12:721-40.

46. Ng T-P, Nyunt MSZ, Feng L, Feng L, Niti M, Tan BY, et al. Multi-domains lifestyle interventions reduces depressive symptoms among frail and pre-frail older persons: Randomized controlled trial. J Nutr Health Aging. 2017;21:918-26.

47. Soysal P, Veronese N, Thompson T, Kahl KG, Fernandes BS, Prina AM, et al. Relationship between depression and frailty in older adults: A systematic review and meta-analysis. Ageing Res Rev. 2017;36:78-87. 